\title{
A qualitative exploration of mothers' and fathers' experiences of having a child with Klinefelter syndrome and the process of reaching this diagnosis
}

\author{
Elyssia Bourke ${ }^{1,2}$, Pamela Snow ${ }^{2}$, Amy Herlihy ${ }^{1}$, David Amor ${ }^{1,3}$ and Sylvia Metcalfe ${ }^{\star, 1,4}$
}

Klinefelter syndrome (KS) is a common genetic condition that is currently under-diagnosed. The phenotype is broad, with physical, medical and psychosocial features ranging from mild to severe. When a child is diagnosed with KS, the parents may spend months to years searching for a diagnosis. This study used a qualitative methods approach to explore parents' experiences of having a child with KS and receiving a diagnosis. Fifteen semistructured one-to-one in-depth interviews were conducted to explore their experiences and views. The interviews were then transcribed, coded and thematically analysed. The interviews revealed that parents had diverse experiences related to: the timing of the diagnosis of their child and reasons why their child was investigated for KS; the information that was provided at the time of diagnosis; the supports that were available and the concerns that parents held for the future of their child. The conclusions from this study were that parents' experiences of having a child with KS and receiving a diagnosis were complex and multifaceted. This experience was shaped by the timing of when the diagnosis was received, who provided the diagnosis, what information was provided from health-care professionals and that which parents may have encountered on the internet. The long-term experiences for parents were also impacted by the level of support they received. These findings have implications for the process by which KS is recognised by the health-care community and supports available for families.

European Journal of Human Genetics (2014) 22, 18-24; doi:10.1038/ejhg.2013.102; published online 22 May 2013

Keywords: Klinefelter syndrome; diagnostic odyssey; non-physical features; mothers; fathers

\section{INTRODUCTION}

Klinefelter syndrome (KS) is the most common chromosomal aberration in men, with an incidence of up to 1 in 450 men. ${ }^{1}$ The majority exhibit a 47,XXY karyotype, although mosaicism or the presence of more than one supernumerary $\mathrm{X}$ chromosome are also observed. $^{2,3}$ The physical and non-physical features, as well as the comorbidities, are highly varied, ${ }^{4-10}$ but most commonly include small testes, gynaecomastia, azoospermia, language and learning problems and behavioural and psychosocial difficulties. ${ }^{11-14}$

In spite of its high incidence, $75 \%$ will remain undiagnosed throughout their lifetime $e^{15,16}$ and only $10 \%$ will be diagnosed before puberty. ${ }^{17}$ Although a diagnosis is infrequently made during childhood or adolescence, parental concern often begins during these early life stages. ${ }^{18}$ Therefore, parents are intrinsically involved in the search for a diagnosis, and their experiences are essential to better understand how improvements can be made to the rate of diagnosis and the diagnostic process. There is limited literature related to parents' experiences of living with a child with KS, or their experiences of arriving at and receiving a diagnosis. Despite preexisting research regarding the diagnostic process for a variety of other conditions, ${ }^{19-21}$ there is limited research focusing specifically on parents' experiences of the diagnostic process of KS and its impact. Of the few published studies that do relate to KS, the focus was on a specific time point of diagnosis such as prenatally, ${ }^{22}$ or studied more than one condition, such as all sex chromosome abnormalities. ${ }^{18}$ The aim of this study was to gain an in-depth understanding of parents' experiences of the diagnostic process and its impact. It is important to understand these factors from the parents' perspective in order to inform clinical practice related to the diagnosis, and to identify resources and supports for parents.

\section{METHODS}

A qualitative methodology was used, utilising a phenomenological framework ${ }^{23,24}$ to explore the 'lived' experience of parents of a child with KS and their pathway to receiving this diagnosis. Recruitment was via email invitation to mothers of boys with KS, and through snowball sampling of the fathers of these boys. The mothers were members of a pre-existing database created to facilitate parents' involvement in research, after they expressed interest during a previous study. ${ }^{6}$ Once recruited, parents were informed that the purpose of the study was to further the current understanding of parents' experiences of having a child with KS and receiving a diagnosis.

In-depth semistructured interviews were conducted between March and July 2012. The interview guide was developed through a review of the literature ${ }^{6,25}$ and discussion among the research team, which included a clinical geneticist, psychologist, speech pathologist, genetics educator and a genetic counsellor. This guide, which is available as Supplementary Material, outlined broad topics to be covered, including an overview of the participant's family structure, information regarding the individual with KS, the diagnostic process, the timing of the diagnosis and the information provided to parents at the time of

${ }^{1}$ Murdoch Childrens Research Institute, Melbourne, Victoria, Australia; ${ }^{2}$ School of Psychology and Psychiatry, Monash University, Bendigo, Victoria, Australia; ${ }^{3}$ Victorian Clinical Genetics Service, Melbourne, Victoria, Australia; ${ }^{4}$ Department of Paediatrics, The University of Melbourne, Melbourne, Victoria, Australia

${ }^{*}$ Correspondence: Professor S Metcalfe, Genetics Education and Health Research, Murdoch Childrens Research Institute, Level West, 5th Floor, MCRI, Royal Children's Hospital, Flemington Road, Parkville, Victoria 3052, Australia. Tel: + 6138341 6309; Fax: + 6138341 6207; E-mail: sylvia.metcalfe@mcri.edu.au

Received 21 December 2012; revised 15 February 2013; accepted 9 April 2013; published online 22 May 2013 
diagnosis and beyond. When new topics arose in the interviews, these topics were added to the interview guide in an iterative process, to allow for further discussion of issues viewed as important by the participants. Interviews were audio-taped, transcribed verbatim and pseudonyms assigned. The data were imported into the software NVivo (QSR International, Melbourne, VIC, Australia) for ease of management. Transcripts were analysed using a constant comparative approach to generate themes. ${ }^{26}$ This involved coding the transcripts and forming initial concepts that emerged from the data, which were further classified into overarching themes through an iterative process of comparing the data. Transcripts were coded independently by EB, SM and PS, with consensus achieved through discussion. Recruitment was concluded when data saturation was reached for the themes presented here. This study was approved by the Royal Children's Hospital Human Research Ethics Committee (HREC) and Monash University HREC.

\section{RESULTS}

Of the 16 eligible mothers contacted, 10 agreed to participate. The other six did not respond even after a second invitation. Six mothers were asked to invite the father of their child to participate; five agreed and were all subsequently interviewed. The remaining four mothers were not asked, as information they provided throughout their interview indicated that their relationship with the father would not facilitate this, or the father was deceased. In total, 15 one-to-one interviews with parents from 10 families took place. The mean age at which parents reported that their children were diagnosed was 7.4 years of age $(S D=10.07)$. The interviews lasted for a mean length of $1 \mathrm{~h}$ and $12 \mathrm{~min}(\mathrm{SD}=15.67)$. See Table 1 for further details.

Interview number 15 , with a mother, Jennifer, whose son had the karyotype of 49,XXXXY was discussed amongst the research team and deemed as inappropriate for inclusion in the study, because of the interview responses, which were beyond the scope of the research questions and the more severe phenotype that was exhibited as a result of his karyotype.

Throughout the interviews, parents discussed a number of issues including those related to the timing of the diagnosis; the process of receiving and coming to terms with the diagnosis, which was an area that parents focused heavily on in the interview; the impact of the diagnosis and their concerns for the future; the information that was provided after the diagnosis and the supports available to parents during and following the diagnosis. These issues are summarised below.

\section{Timing of the diagnosis}

There was a wide range of ages at which parents reported their child was diagnosed. These diagnoses were grouped into three broad categories - prenatal, in which KS was an incidental finding $(n=1)$; early, which occurred before 2 years of age $(n=5)$ and late, which occurred after 2 years of age $(n=4)$. For the family who received a prenatal diagnosis, this occurred incidentally as a result of an amniocentesis performed because of increased maternal age:

Grace: I think I was about 20 weeks [gestation]... when I had an amnio done...purely for my age... and they picked it up through that.

Five families received the diagnosis within the first 2 years of life. For these boys, there was a physical or medical health concern that led parents to seek answers from a health-care professional (HCP). This occurred for Julie's son James, who was investigated because of hypotonia:

Julie: I knew pretty early on... that something wasn't right. He was very floppy and...by six months the milestones that you can measure against weren't really happening for him.... at about ten months he was really struggling to just sit... so we went through a whole range of tests... and at about a year we knew.

Jack received an early diagnosis for his son Patrick, after the paediatrician noted his ambiguous genitalia at birth:

Jack: I remember seeing his genitalia and something rang a bell and I just knew it wasn't normal... [The paediatrician] said 'well, look the first thing we've got to determine is by genes is it a male or a female' so they took the blood then and there.

Table 1 Demographic characteristics of interviewees

\begin{tabular}{|c|c|c|c|c|c|c|c|c|c|}
\hline $\begin{array}{l}\text { Participant } \\
\text { pseudonym }\end{array}$ & $\begin{array}{l}\text { Relationship } \\
\text { to child with KS }\end{array}$ & $\begin{array}{l}\text { Relationship } \\
\text { status }\end{array}$ & $\begin{array}{l}\text { Pseudonym of } \\
\text { child }\end{array}$ & Karyotype & $\begin{array}{l}\text { Age of child } \\
\text { in years }\end{array}$ & $\begin{array}{l}\text { Age of child } \\
\text { at diagnosis }\end{array}$ & $\begin{array}{c}\text { Number of } \\
\text { years since diagnosis }\end{array}$ & State & $\begin{array}{c}\text { Duration of } \\
\text { interview (h:m) }\end{array}$ \\
\hline $\mathrm{Emma}^{\mathrm{a}}$ & Mother & Married & George & $47, X X Y$ & 4 & 18 Months & 2.5 & WA & $1: 27$ \\
\hline Ryan ${ }^{b}$ & Father & & & & & & & & $0: 47$ \\
\hline Chloe $^{c}$ & Mother & Married & Daniel & $47, X X Y$ & 30 & 26 Years & 4 & VIC & $1: 12$ \\
\hline Anna ${ }^{d}$ & Mother & Divorced & Sean & $47, X X Y$ & 37 & 23 Years & 14 & QLD & $1: 06$ \\
\hline Ellen ${ }^{b}$ & Mother & Divorced & Connor & $\begin{array}{l}46, X Y / \\
47, X X Y\end{array}$ & 31 & 9 Years & 22 & QLD & $1: 30$ \\
\hline Barbarab & Mother & Married & Adam & $47, X X Y$ & 25 & 12 Weeks & 24.5 & QLD & $1: 11$ \\
\hline John ${ }^{b}$ & Father & & & & & & & & $1: 23$ \\
\hline Margaret $^{b}$ & Mother & Widowed & Alex & $47, X X Y$ & 22 & 13 Years & 9 & QLD & $1: 27$ \\
\hline Julie & Mother & Divorced & James & $47, X X Y$ & 6 & 12 Months & 5 & NSW & $1: 17$ \\
\hline Allen ${ }^{b}$ & Father & & & & & & & & $1: 12$ \\
\hline Grace $^{\mathrm{b}}$ & Mother & Married & Brent & $47, X X Y$ & 2.5 & Prenatal & 2.5 & VIC & $0: 46$ \\
\hline Steven $^{\mathrm{b}}$ & Father & & & & & & & & $0: 49$ \\
\hline Elizabeth $^{\mathrm{b}}$ & Mother & Married & Patrick & $47, X X Y$ & 17 & 4 Days & 17 & WA & $1: 26$ \\
\hline $\mathrm{Jack}^{\mathrm{b}}$ & Father & & & & & & & & $0: 55$ \\
\hline Jenniferb,e & Mother & Divorced & Julian & $49, X X X X Y$ & 24 & 2-4 Weeks & 24 & QLD & $1: 25$ \\
\hline
\end{tabular}

anterviewed by telephone by $\mathrm{AH}$ with $\mathrm{EB}$ observing.

bInterviewed by telephone by EB.

Interviewed by telephone by EB.
CInterviewed face-to-face by EB.

Interviewed by telephone by EB with AH observing.

eInterview was excluded from results. 
Table 2 Parents' perceptions of the non-physical characteristics of their children

\begin{tabular}{|c|c|}
\hline Feature & Quotes \\
\hline Language & $\begin{array}{l}\text { Emma: At about } 18 \text { months... my girls were talking a lot } \\
\text { more than he was... even when he was born he didn't cry. } \\
\text { Ryan: He has trouble talking... his speech is still way } \\
\text { behind the other kids his age. } \\
\text { Julie: Very placid quiet baby, he didn't make any noises. We } \\
\text { actually thought 'oh my god we've scored the best behaved } \\
\text { baby in the world'... he never used to scream or anything. } \\
\text { Steven: His speech is a bit slower... he talks but he sort of } \\
\text { mumbles it. } \\
\text { Jack: He's not a great reader... reading writing spelling part } \\
\text { he showed no interest... [When he was young] he wasn't as } \\
\text { vocal and he didn't verbalise or speak as much... That's } \\
\text { probably the most noticeable thing, his lack of speech. }\end{array}$ \\
\hline Learning & $\begin{array}{l}\text { Anna: He was getting behind right from the very } \\
\text { beginning... he [could] hardly write a decent sentence. } \\
\text { Chloe: I knew he wasn't doing well [at school]... was } \\
\text { diagnosed with auditory processing [problems]. } \\
\text { Ellen: He didn't do very well at school... his additions were } \\
\text { shocking... he definitely does have learning issues. } \\
\text { Allen: He's got early learning difficulties and he has trouble } \\
\text { reading... auditory processing isn't particularly good. }\end{array}$ \\
\hline $\begin{array}{l}\text { Frustration and } \\
\text { anger }\end{array}$ & $\begin{array}{l}\text { Anna: He got very surly and in terrible bad moods... there } \\
\text { were lots of angry outbursts. } \\
\text { Julie: His frustration has meant he's really lashed out at a } \\
\text { couple of kids physically so that's been a bit of a problem. } \\
\text { Elizabeth: When he was younger he used to get frustrated } \\
\text { very quickly... he can still get upset quite quickly. } \\
\text { Grace: I do notice now that because he can't quite express } \\
\text { himself he gets quite frustrated. } \\
\text { Allen: He did go through a period of being quite angry and } \\
\text { he actually hit one of his best friends at school... he's not } \\
\text { very good at telling you why he gets angry, why he's } \\
\text { upset... he does struggle with trying to communicate how } \\
\text { he's feeling. } \\
\text { Jack: He used to have meltdowns... He would scream and } \\
\text { shout... and go crazy, you couldn't reason with him... He } \\
\text { used to get terribly frustrated... I think a lot of that } \\
\text { frustration was that he found it very difficult to vocalise his } \\
\text { feelings. }\end{array}$ \\
\hline $\begin{array}{l}\text { Anxie } \\
\text { depre }\end{array}$ & $\begin{array}{l}\text { Chloe: Anxiety is part of his makeup... he was quite an } \\
\text { anxious child right through. } \\
\text { Ellen: If people [he didn't know] came into the room he'd } \\
\text { get agitated and start pulling at his hair... his teachers used } \\
\text { to tell me that he would hide behind the bookcases and } \\
\text { wouldn't participate. } \\
\text { Margaret: Prone to being depressed... started cutting him- } \\
\text { self... carving into his arms and legs just to make them } \\
\text { bleed. } \\
\text { Julie: He's very anxious... he's quite aggressive at the } \\
\text { moment because he's anxious. }\end{array}$ \\
\hline Personality & $\begin{array}{l}\text { Emma: He's quite sort of mellow and chilled out and I think } \\
\text { that might have something to do with the KS. } \\
\text { Ryan: He's a very very cautious kid always has been. }\end{array}$ \\
\hline Interpersonal & $\begin{array}{l}\text { Ellen: As far as his nature he's always been a class clown. } \\
\text {... he carries on... still does till this day hence he doesn't } \\
\text { have any friends and can't keep friends. } \\
\text { Elizabeth: He's quite an extrovert-he's very friendly. } \\
\text { Grace: He's shyer than his brother. }\end{array}$ \\
\hline
\end{tabular}

Four families described receiving a late diagnosis. Although they were concerned about their child's development from an early stage, these concerns were a result of non-physical features, were frequently nonspecific and went unrecognised, such as those outlined in Table 2 by a number of families. These parents reported feeling reluctant to seek help initially, or described being 'brushed off' by HCPs. They were also frequently provided with an alternative diagnosis that did not explain the full spectrum of features exhibited in their child. Anna experienced this extended diagnostic process with her child, Sean:

Anna: By grade three I was concerned, so I spoke to the principal and he got Sean tested... he said 'he's come back with results that show he's of below average intelligence but don't go through life holding that against him. Treat him like any other child.' So that's what I did....He went to high school and then I realised he wasn't growing and I went to our local GP [general practitioner]... But he told me that I was neurotic and all mothers wanted their sons to be over six foot tall...He turned to Sean and said look, just to allay your mother's silly fears we'll get you tested.' So he did... and said 'your kid's got no growth hormone'... So he sent me off to see the endocrinologist who had the same opinion as the GP...oh god here's another mother... So he said to me...' he needs a dose of testosterone to kick in his growth hormone'... and then on he did grow... So I just accepted... [that] his inability to do well at school was just the way Sean was made...I was trying not to be one of those pushy mothers.

Sean was diagnosed at 23 years of age after having a testicular biopsy while he had leukaemia. This demonstrated he was infertile, and a subsequent karyotype showed 47,XXY.

Throughout the process to reach a diagnosis, parents encountered a variety of HCPs including GPs, paediatricians, endocrinologists, obstetricians, neurologists, psychiatrists, maternal and child healthcare nurses, speech therapists and psychologists.

The process of receiving and coming to terms with the diagnosis Receiving the diagnosis. Parents' reactions to the diagnosis varied, and were heavily dependent on when they received the diagnosis and whether they had previously considered that there might be something wrong with their child. The three parents who received an unexpected postnatal diagnosis were shocked, such as Jack, whose son Patrick was diagnosed unexpectedly 4 days after birth:

Jack: The [paediatrician] said to us 'oh it's not good, you know, there's a big problem' and I thought I had a spastic child or someone that was going to die within the month or year...And then as soon as they mentioned it was a genetic thing...I knew once something's genetic you can't change it...I knew it was a life sentence for him... and [that] shocked me the most... when it was confirmed 'til the day he dies Patrick's gonna have this.

For those parents who had been searching for a diagnosis, receiving one came as a relief, as it confirmed that their concerns were not unfounded, and allowed them to move forward with management for their child. Allen, whose son James was diagnosed after a period of exploring a number of other diagnoses explained his feelings about receiving a diagnosis of $\mathrm{KS}$ :

Allen: It was actually a relief (laughs). We read about Klinefelter's a little bit and then realised it's not as bad as some of the other things that we thought it was... So yeah, it was a big relief that it wasn't life threatening and that there are things we can do to combat it.

In contrast, Emma outlined her reaction, which demonstrates that although the diagnosis can provide initial relief, this may be fleeting when the ramifications are considered more closely:

Emma: To begin with it was actually a relief... And then the more she talked to us about him not having many options open to him and... you know, 'don't expect him to go to uni and he might not make friends very easily and he is going to have trouble at school'... She literally said to me, 'someone's got to drive the rubbish trucks'... We got really depressed then. 
Coming to terms with the diagnosis - 'a grieving process'. After receiving the diagnosis, parents discussed how they came to terms with it. Parents reported struggling if they received an unexpected diagnosis:

Elizabeth: I did find bonding quite difficult, at first... [It] sounds awful but I used to hope I would just wake up and he would have passed away in his sleep...I just had this vision of my child being really freaky... But that stage... didn't last long-it was obviously one of the processes I had to go through, you know, a grieving process.

For those parents that received a diagnosis after they had been searching for one, the process of coming to terms with the diagnosis was considerably easier:

Anna: It came as a terrible shock [to Sean] ...I wasn't [shocked] because it all fitted the pattern... I did sort of know about KS and I thought oh yes that sort of makes sense.

Impact of the diagnosis. An important issue discussed by a number of parents was that having an increased awareness of their child's problems impacted their behaviour towards their child, and their interactions with each other, as well as their lives in general:

Elizabeth about Patrick: You know the repercussion... is that...I was always looking out for something when he was young-I never had that joy of just sailing through and enjoying every minute. I was always on the lookout to see if he was falling behind somewhere and looking out for something that we could do to help him.

Some parents discussed how they had altered their parenting strategies:

Julie about James: Having an awareness of the diagnosis and what that might mean for him has meant that a lot of the behaviour that's come since then I treat differently because I know it's not just him being naughty...I guess it's just having to adapt the way we manage him and the way we guide him.

Parents also spoke about the effect that the diagnosis had on their relationships and their ability to work:

Julie: I think his diagnosis was a big part of our marriage falling apart. Not the diagnosis itself, but the stress and anxiety that we went through while we were figuring out what the hell was going on.

Steven about Brent: It's hard with work...because they don't understand...I've had my boss crack the shits [ie, get angry] heaps of times... and I've said 'well if you can't understand, I can't work here.' I've gave notice to him and he's come round and he's said 'well I know you've got problems with your kid and I want you to work here cause you make me money.' And I said 'well is that all you think, that I make you money? What about me and my wife? We go through a lot with Brent'... The other painter sort of understands but my boss doesn't. He doesn't want to understand.

\section{Concerns for the future}

Parents also outlined their concerns about the future outlook for their child.

Chloe about Daniel: We're really hopeful that he finds a foothold in life because he's got big ambitions and wants to do well... But we're also realistic enough to know that you just sort of take this all as it comes, and his life will sort of work out how it does.

Their concerns also included issues related to fertility, sexuality and masculinity:

Steven about Brent: Well the main thing that worried me was that he can't have kids. How am I meant to tell him?

Jack about Patrick: Being a man... I'll tell you men are obsessed with their penises, they are obsessed with their genitalia... I feel for Patrick if he ever has to shower naked next to another man, because he would be ridiculed, he would be laughed at, he would be made fun of, because his penis is that small, and that shape it's just not normal.

Ellen about Connor: As soon as Connor was diagnosed, his father straight away said 'he's gonna be a homosexual' and just sort of didn't want to know him.

Grace about Brent: Steven was really concerned about him being gay... I think his first reaction is because he's not gonna have enough testosterone and he might grow these manboobs and stuff like that he was worried that he might turn gay and I'm thinking 'well you know, the healthiest blokes out there can turn gay.'

\section{Information provision}

Many parents had vivid memories about the information that was provided to them by HCPs at the time of diagnosis and beyond, and some reported the negative or out-dated focus of this information:

Barbara about Adam, who was diagnosed 25 years ago at 12 weeks of age: The thing that sticks out was that there would be no body hair, he would be a homosexual, he would have small genitals, and a low IQ.

Emma, about George, diagnosed 2.5 years ago at 18 months of age by a paediatrician: She explained to us what it meant in a very negative way... The way it was delivered, it was a death sentence... it was terribly upsetting to hear.

In contrast, parents who had contact with a genetics specialist reported that helpful and satisfying information was provided:

Grace about Brent, diagnosed 2.5 years ago at 2 years and 6 months: We went off to the geneticist and...she was really good, she explained everything...And she gave me a little book on Klinefelter's as well.

Elizabeth about Patrick, diagnosed 17 years ago, four days after birth: I know the genetics specialist that we saw said some very positive things.

Furthermore, parents who were given information from HCPs through brochures or booklets generally discussed receiving a more objective overview of the condition, as noted above by Grace and below by Ellen:

Ellen about Connor, who was diagnosed 22 years ago at age 9: I was given a booklet by the paediatrician... That book was good, it was a basic booklet... I could understand everything... It did state all about his learning difficulties and his antisocial behaviour.

Of those parents whose children were diagnosed following the availability of the internet, most reported finding negative, out-dated and frightening information: 
Julie about James, diagnosed 5 years ago at 12 months of age: Even now, I mean I know a lot more, but going back and looking at some of those sites, medically they're not even correct...it's absolutely hopeless and a lot of it is quite frightening as well.

Steven about Brent, who was diagnosed antenatally two and a half years ago: We had a look at it and it wasn't a good thing because the more you read the more shocked you get.

\section{Support}

It was evident through parents' accounts that receiving and coming to terms with a diagnosis was the start of another challenging stage in the diagnostic process. Parents required assistance from both formal support services and their personal support networks. They outlined a range of experiences in both of these domains. Formalised support, specifically support groups, KS associations and schools were seen as essential to successful outcomes regarding parents' adjustment in a number of cases:

Elizabeth: Klinefelter syndrome and associates...the website...they were my saving grace until Patrick was a teenager... They were absolutely fantastic and I think they got me through the first few years... They really were absolutely superb.

Grace: I joined a support group with other people with Klinefelter's... and it was just really good to hear what other people are saying about their kids... things that are happening to their kids at different ages.

However, other parents described having experienced a lack of formalised support:

Chloe: We found at the support group...the men that were at the severe end of things [would go] ... and we came to the conclusion that anyone that is coping wouldn't go...It wasn't a good thing...to go.

Parents' personal supports and their children's supports were also seen as extremely important in allowing families to cope with the impact of $\mathrm{KS}$ :

Margaret: His brothers...they were great, they would take him to the rugby and they...taught him to surf and would do boy things with him... He had that good balanced support.

Although some parents reported having had a negative experience with their social supports.

John about Adam: It makes it hard when [family and friends] tell you they're there to support you, and as soon as you ask them something, well it must have been the invisible woman I was talking to- they're gone and you don't hear from them again... That was something I felt very hurt with, was the absolute and utter lack of support.

\section{Early diagnosis}

For many parents, reflecting on their own experiences revealed their views regarding the benefits of early diagnosis, and how they thought that this would benefit parents in the future:

Grace: I reckon they should be screened at birth... it will help so many parents out... instead these poor kids are struggling so hard at school... and it will stop people thinking 'what's wrong with this child and why isn't it talking properly'... it'd be peace of mind.

Anna: I think [early diagnosis] would give you time to adjus$\mathrm{t}$... knowledge is power and having the knowledge would help you tackle some of the issues.

Allen: I'd say a definite yes... early screening should be done... I would say at 12 months [of age] ... it just takes out the worry like in our case we knew something was wrong we just didn't know what... if there's something wrong... blood tests should be done.

\section{DISCUSSION}

This study explored the process that parents underwent to obtain a diagnosis of KS for their child and, for many, the diagnostic odyssey that they experienced throughout this time. Parents experienced difficulties eliciting a diagnosis, obtaining objective information regarding the diagnosis and accessing support services.

These findings suggest that the circumstances in which parents receive the diagnosis influences their initial reaction to that diagnosis, something that is mirrored elsewhere in the 'breaking bad news' literature. ${ }^{27}$ Parents in this study who received the diagnosis unexpectedly described feeling shocked, which is congruent with previously reported initial grief reactions for individuals and parents receiving an unexpected chronic diagnosis. ${ }^{28}$

For those parents who reported being aware that something was wrong before a diagnosis being elicited, there were two distinct emotional reactions. All reported having been initially relieved, but only those who described viewing the diagnosis as consistent with their expectations continued to be relieved, or viewed the diagnosis as a positive outcome. On learning that KS was a genetic condition that their child would have for the rest of their lives, parents described reactions that included concern, confusion, sadness and depression. Previous studies related to genetic conditions including fragile $\mathrm{X}$ syndrome $(\mathrm{FXS})^{18}$ and Turner syndrome ${ }^{18}$ have also demonstrated varied individual and parental responses to receiving a chronic diagnosis, depending on the expectations of the type of condition that would be diagnosed, and a similar pattern has been reported in relation to other chronic conditions including type 2 diabetes mellitus and attention deficit hyperactivity disorder. ${ }^{29,30}$ Therefore, the ramifications of providing families with a genetic diagnosis need to be considered; parents' searching for an explanation for their child's difficulties does not necessarily translate into a readiness to receive a genetic diagnosis, which has life-long implications for their child. Therefore, the same breaking bad news protocols that would be utilised when providing an unexpected diagnosis are important for these families; even if the HCP thinks that the parent was 'pushing' to obtain a diagnosis.

Almost all parents indicated that they had been provided with some incorrect or misleading information by HCPs, or that the information presented represented the 'worst case scenario' for their child, as has been described in earlier studies related to KS and other chromosome aneuploidies such as triple X syndrome. ${ }^{18}$ It would seem from parents' experiences that HCPs who did not have a thorough understanding of KS, or whose understanding was established during medical training and which had not been more recently updated, provided inappropriate information to parents. Owing to the everchanging understanding of genetic conditions, HCPs need to keep upto-date with this knowledge, or be willing to refer families receiving a genetic diagnosis to a specialist. It has been previously reported that if 
information is provided by a genetics specialist, individuals are less likely to have unanswered questions about their diagnosis ${ }^{31}$ and this was noted by two of the three families in this study who saw a geneticist. Therefore, a genetic specialist could be an appropriate referral pathway for HCPs who are unsure about the intricate details of a genetic condition such as KS.

Furthermore, parents reported that HCPs, including GPs and paediatricians, provided information indicating that their knowledge of the treatment and management of the condition was out-dated. As there have been considerable advancements in recent years with the ready availability of testosterone replacement therapy and fertility treatments, as well as allied health services such as speech and occupational therapy, it is important that HCPs are aware of these options and use the appropriate referral pathways to facilitate optimal management for these individuals. In many cases, because of a lack of knowledge of these developments in treatment and management, many HCPs are unaware that there are options available to improve the quality of life for individuals with chronic genetic conditions such as KS. Therefore, they are unlikely to refer individuals with the condition, as they are not aware of treatment benefits. As well as increasing the understanding of the need for appropriate referral pathways, it is essential that HCPs including GPs and paediatricians are offered opportunities to allow them to stay up-to-date with the treatment, management and future outlook for KS and other genetic conditions. By providing continued education programs, such as education sessions or online modules on genetic conditions, the continuity and quality of care provided after the initial treatment and management regimen has been initiated by a genetic specialist or endocrinologist, is likely to be increased.

It has been noted that rates of elective termination in KS after prenatal diagnosis are extremely high, with rates of $70 \%$ being recorded. ${ }^{5}$ Although these levels have fallen in recent years, termination rates still range from 30 to $60 \% .^{32-34}$ Previous research indicates that whether a pregnancy is aborted is heavily dependent on the post-test counselling provided. If the counselling is provided by a genetics expert, the pregnancy is less likely to be terminated than if the diagnosis was provided by a general practitioner. ${ }^{5,35}$ This further illustrates the need for HCPs to appropriately refer parents who have a child diagnosed with $\mathrm{KS}$, particularly in the prenatal period, to ensure that appropriate and up-to-date prenatal counselling regarding the condition can be provided.

Previous studies have also commented on the under-diagnosis and delay in diagnosis that occurred for many individuals with KS. ${ }^{15-17,22,36}$ This qualitative study provides important insight into parents' experiences of the vital role that the presence of obvious or explicit physical features in childhood has in facilitating a timely diagnosis for their child. Under-diagnosis and delay in diagnosis for individuals with KS is more likely in the presence of non-classical or nonspecific physical features, or when only non-physical features such as language and learning problems, or other features outlined in Table 2 are present. This may be due to HCPs only considering the 'classic' KS phenotype, which has a strong focus on physical features, many of which are not evident until early adolescence. This phenomenon has been previously reported in research related to FXS, another genetic syndrome, which can also present with nonspecific non-physical features. ${ }^{37}$ Considering the high prevalence of many of the features listed in Table 2 in a wide variety of conditions, as well as the general population, it is understandably difficult for HCPs to attribute these features to a specific syndrome. Furthermore, many of these features are highly subjective, their presence is difficult to detect, and severity difficult to assess.
However, it is worth considering why many classic presentations of genetic syndromes, including KS and FXS, have such a limited focus on the non-physical aspects of the condition and whether future generations of HCPs could be educated with a stronger focus on these non-physical features, to ensure that they are better recognised.

Parents also reported their concerns regarding the sexuality, masculinity and fertility of their child. Both mothers and fathers were concerned about these aspects, and spoke extensively about these issues in the interviews. It was reported that this is something that HCPs had discussed at length with parents, specifically the notion that their son may be more likely to be homosexual, even though this has now been refuted in the medical literature. ${ }^{18,38}$ Parents, and in particular fathers, wanted to explore the issues surrounding sexual development, functioning and fertility for their $\operatorname{son}^{39}$ and this was understandably one of the key concerns that they had for the future of their child. In previous studies, parents have reported experiencing a 'crisis of infertility' related to the inability of their son to have a family in the future. ${ }^{39}$ Although this crisis was not explicitly raised by parents in this study, some comments by parents combined with the shock and sadness they reported experiencing when receiving the diagnosis, may have been linked to this loss of fertility for their child, and their own grief related to the loss of potential future grandchildren.

It is important to acknowledge a number of limitations in this study. The sample size was small as this was a qualitative study, and therefore findings cannot be generalised. There were more mothers than fathers, and thus the results may not accurately represent the views of fathers. Furthermore, none of the fathers who were interviewed were the primary caregiver of the child with KS.

Also, a number of the parents interviewed received the diagnosis of KS for their child more than a decade earlier. However, previous research has demonstrated that despite the length of time since diagnosis for some parents, their recollections of the process of diagnosis were very strong; these have been described as 'flash bulb memories ${ }^{40}$ and noted in other studies. ${ }^{41,42}$

All of the mothers who were interviewed were recruited through a pre-existing database. This database was created when mothers who were interested in KS research contacted a senior researcher. ${ }^{6}$ Therefore, there may have been a self-selection bias regarding who participated in the research and these mothers may represent a biased sample of parents of a child with KS.

\section{CONCLUSION}

$\mathrm{KS}$ is an important condition that is currently under-diagnosed and of which there is a lack of awareness, especially with respect to its associated non-physical features. As a result, parents often experienced a frustrating and complex pathway to diagnosis. HCPs' awareness of KS, especially of the non-physical features could be increased, and provision of information once a diagnosis is elicited could be improved. Consideration of a stronger focus on the importance of non-physical features in the recognition of genetic syndromes such as KS during medical training may improve its detection. An emphasis on these aspects to HCPs may also improve rates of diagnosis. Further research into these areas would be beneficial, and a larger quantitative study focusing on parents' experiences related to having a child with $\mathrm{KS}$ is currently being conducted.

\section{CONFLICT OF INTEREST}

The authors declare no conflict of interest. 


\section{ACKNOWLEDGEMENTS}

We acknowledge the parents who participated in this study, without whom this work would not be possible. Also, all individuals at the Murdoch Childrens Research Institute and Monash University who helped bring this study to completion, especially Dr Ned Douglas. This work was supported by the Victorian Government's Operational Infrastructure Support Program.

1 Herlihy AS, Halliday JL, Cock ML, McLachlan RI: The prevalence and diagnosis rates of Klinefelter syndrome: an Australian comparison. Med J Aust 2011; 194: 24-28.

2 Rey RA, Gottlieb S, Pasqualini T et al: Are Klinefelter boys hypogonadal? Acta Paediatr 2011; 100: 830-838.

3 Boada R, Janusz J, Hutaff-Lee C, Tartaglia N: The cognitive phenotype in Klinefelter syndrome: a review of the literature including genetic and hormonal factors. Dev Disabil Res Rev 2009; 15: 284-294.

4 Zinn AR, Ramos P, Elder FF, Kowal K, Samango-Sprouse C, Ross JL: Androgen receptor CAGn repeat length influences phenotype of 47,XXY (Klinefelter) syndrome. J Clin Endocrinol Metab 2005; 90: 5041-5046.

5 Bojesen A, Juul S, Gravholt $\mathrm{CH}$ : Prenatal and postnatal prevalence of Klinefelter syndrome: a National Registry Study. J Clin Endocrinol Metab 2003; 88: 622-626.

6 Herlihy AS, McLachlan RI, Gillam L, Cock ML, Collins V, Halliday JL: The psychosocial impact of Klinefelter syndrome and factors influencing quality of life. Genet Med 2011; 13: 632-642.

7 Fennoy I: Testosterone and the child (0-12 years) with Klinefelter syndrome (47XXY): a review. Acta Paediatr 2011; 100: 846-850.

8 Bojesen A, Høst C, Gravholt CH: Klinefelter's syndrome, type 2 diabetes and the metabolic syndrome: the impact of body composition. Mol Hum Reprod 2010; 16 396-401.

9 Bojesen A, Juul S, Birkebæk N, Gravholt $\mathrm{CH}$ : Increased mortality in Klinefelter syndrome. J Clin Endocrinol Metab 2004; 89: 3830-3834.

10 Bojesen A, Juul S, Birkebæk NH, Gravholt CH: Morbidity in Klinefelter syndrome: a Danish Register Study based on hospital discharge diagnoses. J Clin Endocrinol Metab 2006; 91: 1254-1260.

11 Bojesen A, Gravholt CH: Klinefelter syndrome in clinical practice. Nat Clin Pract Urol 2007; 4: 192-204.

12 Geschwind DH, Boone KB, Miller BL, Swerdloff RS: Neurobehavioral phenotype of Klinefelter syndrome. Ment Retard Dev Disabil Res Rev 2000; 6: 107-116.

13 Leggett V, Jacobs P, Nation K, Scerif G, Bishop DVM: Neurocognitive outcomes of individuals with a sex chromosome trisomy: $\mathrm{XXX}, \mathrm{XYY}$, or XXY: a systematic review. Dev Med Child Neurol 2010; 52: 119-129.

14 Turriff A, Levy HP, Biesecker B: Prevalence and psychosocial correlates of depressive symptoms among adolescents and adults with Klinefelter syndrome. Genet Med 2011 13: 966-972.

15 Herlihy AS, Gillam L, Halliday JL, McLachlan RI: Postnatal screening for Klinefelter syndrome: is there a rationale? Acta Paediatr 2011; 100: 923-933.

16 Morris JK, Alberman E, Scott C, Jacobs P: Is the prevalence of Klinefelter syndrome increasing? Eur J Hum Genet 2007; 16: 163-170.

17 Bojesen A, Stochholm K, Juul S, Gravholt CH: Socioeconomic trajectories affect mortality in Klinefelter syndrome. J Clin Endocrinol Metab 2011; 96 2098-2104.

18 Whitmarsh I, Davis AM, Skinner D, Bailey DB Jr: A place for genetic uncertainty: parents valuing an unknown in the meaning of disease. Soc Sci Med 2007; 65: 1082-1093.

19 Carmichael B, Pembrey M, Turner G, Barnicoat A: Diagnosis of fragile-X syndrome: the experiences of parents. J Intellect Disabil Res 1999; 43: 47-53.

20 Fredheim T, Lien L, Danbolt LJ, Kjønsberg K, Haavet OR: Experiences with general practitioners described by families of children with intellectual disabilities and challenging behaviour: a qualitative study. BMJ Open 2011; 1: 1-7.
21 Rosenthal ET, Biesecker LG, Biesecker BB: Parental attitudes toward a diagnosis in children with unidentified multiple congenital anomaly syndromes. Am J Med Genet 2001; 103: 106-114.

22 Pieters J, Kooper A, Eggink AJ et al: Parent's perspectives on the unforeseen finding of a fetal sex chromosomal aneuploidy. Prenat Diagn 2011; 31: 286-292.

23 Crotty M: The Foundations of Social Research: Meaning and Perspective in the Research Process, 1st edn London: SAGE Publications, 1998.

24 Robinson A: Phenomenology; In: Cluett ER, Bluff R (eds). Principles and Practice of Research in Midwifery. Churchill Livingstone Elsevier, 2006; pp 187-202.

25 Wong SH: Diagnosing Duchenne muscular dystrophy and parents' views on screening: a Victorian perspective. Advanced Medical Science (AMS) thesis, University of Melbourne, Melbourne 2011.

26 Charmaz K: Constructing Grounded Theory: A Practical Guide through Qualitative Analysis, 1st edn London: SAGE Publications, 2006.

27 Shaw J, Dunn S, Heinrich P: Managing the delivery of bad news: an in-depth analysis of doctors' delivery style. Patient Educ Couns 2012; 87: 186-192.

28 Salander P: Bad news from the patient's perspective: an analysis of the written narratives of newly diagnosed cancer patients. Soc Sci Med 2002; 55: 721-732.

29 Peel E, Parry O, Douglas M, Lawton J: Diagnosis of type 2 diabetes: a qualitative analysis of patients' emotional reactions and views about information provision. Patient Educ Couns 2004; 53: 269-275.

30 Young S, Bramham J, Gray K, Rose E: The experience of receiving a diagnosis and treatment of ADHD in adulthood: a qualitative study of clinically referred patients using interpretative phenomenological analysis. J Atten Disord 2008; 11: 493-503.

31 Van Engelen K, Baars MJ, van Rongen LT, van der Velde ET, Mulder BJ, Smets EM: Adults with congenital heart disease: patients' knowledge and concerns about inheritance. Am J Med Genet A 2011; 7: 10.

32 Denschlag D, Tempfer C, Kunze M, Wolff G, Keck C: Assisted reproductive techniques in patients with Klinefelter syndrome: a critical review. Fertil Steril 2004; 82: 775-779.

33 Gruchy N, Vialard F, Decamp M et al: Pregnancy outcomes in 188 French cases of prenatally diagnosed Klinefelter syndrome. Hum Reprod 2011; 26: 2570-2575.

34 Mansfield C, Hopfer S, Marteau TM: Termination rates after prenatal diagnosis of Down syndrome, spina bifida, anencephaly, and Turner and Klinefelter syndromes: a systematic literature review. Prenat Diagn 1999; 19: 808-812.

35 Marteau T, Nippert I, Hall S et al: Outcomes of pregnancies diagnosed with Klinefelter syndrome: the possible influence of health professionals. Prenat Diagn 2002; 22: 562-566.

36 Visootsak J, Ayari N, Howell S, Lazarus J, Tartaglia N: Timing of diagnosis of 47, XXY and 48,XXYY: a survey of parent experiences. Am J Med Genet A 2013; 161: 268-272.

37 Bailey DB, Skinner D, Hatton D, Roberts J: Family experiences and factors associated with the diagnosis of fragile X syndrome. J Dev Behav Pediatr 2000; 21: 315-321.

38 Abramsky L, Hall S, Levitan J, Marteau TM: What parents are told after prenatal diagnosis of a sex chromosome abnormality: interview and questionnaire study. $B M$ 2001; 322: 463-466.

39 Borelli JB, Bender BG, Puck MH, Salbenblatt JA, Robinson A: The meaning of early knowledge of a child's infertility in familes with $47, X X Y$ and $45, X$ children. Child Psychiatry Hum Dev 1984; 14: 215-222.

40 Quine L, Rutter DR: First diagnosis of severe mental and physical disability: a study of doctor-parent communication. J Child Psychol Psychiatry 1994; 35 : 1273-1287.

41 Hill V, Sahhar M, Aitken MA, Savarirayan R, Metcalfe S: Experiences at the time of diagnosis of parents who have a child with a bone dysplasia resulting in short stature. Am J of Med Genet A 2003; 122: 100-107.

42 Skotko BG, Levine SP, Goldstein R: Having a son or daughter with Down syndrome: perspectives from mothers and fathers. Am J Med Genet A 2011; 155 2335-2347.

Supplementary Information accompanies this paper on European Journal of Human Genetics website (http://www.nature.com/ejhg) 